\title{
Tympanic Membrane Retractions in patients with Williams Syndrome: A Controlled Study
}

\author{
Marcelo Wierzynski Oliveira ${ }^{10}$ Joel Lavinsky ${ }^{2,3}$ \\ Luiz Lavinsky ${ }^{10}$ \\ ${ }^{1}$ Department of Otolaryngology, Universidade Federal do Rio Grande \\ do Sul, Porto Alegre, RS, Brazil \\ 2 Department of Morphological Sciences, Universidade Federal do Rio \\ Grande do Sul, Porto Alegre, RS, Brazil \\ ${ }^{3}$ Santa Casa de Misericordia de Porto Alegre, Porto Alegre, RS, Brazil \\ ${ }^{4}$ School of Medicine, Universidade Federal do Rio Grande do Sul, \\ Porto Alegre, RS, Brazil \\ ${ }^{5}$ Department of Genetics, Universidade Federal do Rio Grande do Sul, \\ Porto Alegre, RS, Brazil \\ Int Arch Otorhinolaryngol 2021;25(3):e443-e445.
}

Marcel Machado Valerio ${ }^{4(} \quad$ Temis Maria Felix ${ }^{5}$

Address for correspondence Joel Lavinsky, MD, MSc, Departamento de Ciências Morfológicas, Universidade Federal do Rio Grande do Sul, Rua Sarmento Leite, 500, Porto Alegre, RS 90040-060, Brazil (e-mail: jlavinskybr@yahoo.com).

\author{
Abstract \\ Keywords \\ - williams syndrome \\ - elastin \\ - chronic otitis media
}

Introduction The role of elastin in tympanic retractions and chronic otitis media is not well established. Williams Syndrome (WS), a pathology related to a mutation in the elastin gene, could generate tympanic retractions.

Objective To compare the prevalence of tympanic retractions among patients with WS and controls.

Methods WS patients ( $n=43$ ears) and controls ( $n=130$ ears) were evaluated by digital otoscopic examination and the degree of tympanic membrane retraction was classified by 2 blinded experienced otolaryngologists.

Results The agreement rate between the evaluators was $71.1 \%$ for pars tensa and $65 \%$ for pars flaccida retraction $(p<0.001)$. The pars tensa and pars flaccida retractions are present in patients with WS after an adjusted residue of respectively - 2.8 and - 2.6 $(p=0.011$ and $p=0.022)$ compared with controls.

Conclusions Tympanic membrane retractions are not more common in the WS group when compared with controls.

\section{Introduction}

Tympanic membrane (TM) retraction is the result of middle ear negative persistent pressure and could be related to recurrent acute otitis media and otitis media with effusion. ${ }^{1-3}$

The continuum theory refers to an initial triggering factor leading to a functional or mechanical Eustachian tube dysfunction, which would generate a negative middle ear pressure and an inflammatory process of the subepithelial space; then thickening and vasodilation followed by a plasma extravasation occurs.

received

April 8, 2020

accepted

June 25, 2020

published online

October 15, 2020
The role of elastin in the tympanic retractions and in the genesis of cholesteatoma has been evaluated along with other components of the tympanic membrane, such as collagen, fibroblasts, macrophages and inflammatory mediators based on histopathology. ${ }^{4-7}$

There are different amounts of elastin in the tympanic membrane of animal models, but there is no evidence of an increased susceptibility to chronic otitis media. ${ }^{8}$ Ruah et al demonstrated the persistence of mesenchyme, inflammation and changes in collagen and elastin as the possible origin of the tympanic retractions. ${ }^{6}$ These authors considered that the delay

(c) 2020. Fundação Otorrinolaringologia. All rights reserved.

This is an open access article published by Thieme under the terms of the Creative Commons Attribution-NonDerivative-NonCommercial-License, permitting copying and reproduction so long as the original work is given appropriate credit. Contents may not be used for commercial purposes, or adapted, remixed, transformed or built upon. (https://creativecommons.org/ licenses/by-nc-nd/4.0/)

Thieme Revinter Publicações Ltda., Rua do Matoso 170, Rio de Janeiro, RJ, CEP 20270-135, Brazil 
in absorption and differentiation of mesenchyme could be responsible for the maturation inability of elastin fibers in the tympanic membrane. It seems that the inflammation process would make the mesenchyme persist in the middle ear, which in turn would delay or disrupt the normal elastin fibers in the tympanic membrane. ${ }^{6}$

Since there is no evidence about the role of elastin regarding tympanic retractions, we evaluated patients with Williams Syndrome (WS) based on knowledge about a mutation in the elastin gene on chromosome 7 (ELN gene). This mutation leads to phenotypic cardiovascular, neurological and endocrine changes. Thus, our hypothesis is that WS could have also some increased susceptibility to tympanic retractions based on deficiency of the elastin gene.

\section{Materials and Methods}

We performed an observational, cross-sectional and controlled study. The present research was approved by the Ethics Research Committee of the Hospital de Clínicas de Porto Alegre and all participants signed the informed consent form.

All participants with WS included in the present study were previously registered at the department of genetics $(n=16)$ and at the Brazilian Association of Williams Syndrome (ABSW, in the Portuguese acronym) $(n=6)$ regardless of age, gender, or clinical condition. The control group was paired based on age. These controls had no diagnosis of WS or other genetic syndromes.

The otoscopic examination with digital video recording was performed by the author and later evaluated by two blinded otolaryngologists. The classification was based on the Sadé ${ }^{9}$ and $\operatorname{Tos}^{3}$ classification criteria. The Sadé classification of pars tensa retraction is determinate as Grade 1 (slight retraction of the TM over the annulus), Grade 2-severe retraction (the TM touches the long process of the incus), Grade 3 - atelectasis (the TM touches the promontory) and Grade 4-adhesive otitis (TM adherent to the promontory). The Tos classification of pars flaccida retraction is determinate as Grade 1 (small attic dimple), Grade 2 (pars flaccida retracted maximally and dreaped over neck of malleus), Grade 3 (as grade 2 with erosion of outer attic wall) and Grade 4 (deep retraction with unreacheable accumulated keratin).

The Mann-Whitney test was used to analyze categorical variables and the Student $t$-test was used for continuous variables. The kappa index was used to assess agreement between the two blinded evaluators. The chi-squared test (correction continuity) was used to make comparisons between groups. Sample size calculation was performed to detect a difference of $20 \%$ between the two groups (power of $80 \%$ and alfa $=5 \%$ ) and resulted in 63 patients (cases $=21$ and controls $=42$ ). The data was analyzed by PASW Statistics for Windows, version 18.0 (SPSS Inc., Chicago, IL, USA)

\section{Results}

A total of 173 ears ( $n=43$ WS; $n=130$ controls) were included and only 1 was excluded due to acute external otitis.

There were no significant differences between groups at baseline ( - Table 1), except regarding the history of otologic disorders (WS $=50 \%$ versus Controls $=25 \% ; p=0.032$ ). Most of these complaints were subjective and related to hyperacusis in the WS group.

About the classification of pars tensa retractions, ${ }^{9}$ the agreement rate was of $68.6 \%$ for controls, $78.8 \%$ in the WS group, and $71.1 \%$ when grouped. In the classification of pars flaccida retractions, ${ }^{3}$ the agreement rate was of $64.8 \%$ for controls and of $48.2 \%$ for the WS group.

According to the Sadé classification, there was an adjusted residue of -3.2 for pars tensa retractions in patients with WS $(p=0.003)$ regarding evaluator \#1. This means that in the presence of retractions of pars tensa, it tends to the control group, and to the WS group when there is absence of retraction. Regarding evaluator \#2, the adjusted residue was -2.8 for TM with pars tensa retractions in the WS group $(p=0.009)$, similar to evaluator \#1. When the evaluators agreed on the classification of retractions according to the Sadé Rating, the adjusted residual was -2.8 for absence of retraction in patients with WS $(p=0.011)$. Thus, the presence of pars tensa retractions is more common in the control group (-Table 2 ).

According to the Tos classification, there was an adjusted residue of -2.6 for pars flaccida retractions in patients with WS $(p=0.017)$, which means that the presence of pars flaccida retractions is more common in the control group (evaluators \#1 and \#2). When the evaluators agreed about the Tos classification, the adjusted residual is -2.6 for absence of retraction in patients with WS $(p=0.022)$ ( - Table 3 and 4$)$.

\section{Discussion}

The higher prevalence of a history of otologic problems in patients with WS is consistent with the literature. Most of the complaints are related to hyperacusis and would need a

Table 1 Baseline characteristics

\begin{tabular}{|l|l|l|l|}
\hline Variables & $\begin{array}{l}\text { Controls } \\
n=67 \\
n(\%) \text { or average }\end{array}$ & $\begin{array}{l}\text { Williams Syndrome } \\
n=22 \\
n(\%)\end{array}$ & $p$-value (lower limit-upper Limit) \\
\hline Female & $31(48 \%)$ & $6(27 \%)$ & $0.135(0.135-0.143)^{*}$ \\
\hline Age & 12.66 & 12.73 & $0.974^{\mu}$ \\
\hline History of oologic disorders & $16(25 \%)$ & $11(50 \%)$ & $0.032(0.028-0.037)^{*}$ \\
\hline History of nasosinusal disorders & $15(23 \%)$ & $6(27 \%)$ & $0.768(0.758-0.779)^{*}$ \\
\hline
\end{tabular}

${ }^{*}$ Mann-Whitney.

$\mu$ Student $t$-test. 
Table 2 Agreement between evaluators for groups - Sadé classification

\begin{tabular}{|c|c|c|c|c|c|c|c|}
\hline & & & \multicolumn{2}{|l|}{ Evaluator 2} & \multirow[t]{2}{*}{ Total } & \multirow[t]{2}{*}{ Kappa } & \multirow[t]{2}{*}{ p-value } \\
\hline & & & Without retraction & With retraction & & & \\
\hline \multirow[t]{3}{*}{ Normal } & \multirow[t]{2}{*}{ Evaluator 1} & Without retraction & 86 & 8 & 94 & \multirow[t]{3}{*}{0.686} & \multirow[t]{3}{*}{$<0.001$} \\
\hline & & With Retraction & 8 & 27 & 35 & & \\
\hline & \multicolumn{2}{|l|}{ Total } & 94 & 35 & 129 & & \\
\hline \multirow[t]{3}{*}{ Williams Syndrome } & \multirow[t]{2}{*}{ Evaluator 1} & Without retraction & 41 & 1 & 42 & \multirow[t]{3}{*}{0.788} & \multirow[t]{3}{*}{$<0.001$} \\
\hline & & With Retraction & 0 & 2 & 2 & & \\
\hline & \multicolumn{2}{|l|}{ Total } & 41 & 3 & 44 & & \\
\hline
\end{tabular}

Table 3 Agreement between evaluators for groups -Tos classification

\begin{tabular}{|c|c|c|c|c|c|c|c|}
\hline & & & \multicolumn{2}{|l|}{ Evaluator 2} & \multirow[t]{2}{*}{ Total } & \multirow[t]{2}{*}{ Kappa } & \multirow[t]{2}{*}{$p$-value } \\
\hline & & & Without retraction & With retraction & & & \\
\hline \multirow[t]{3}{*}{ Controls } & \multirow[t]{2}{*}{ Evaluator 1} & Without retraction & 93 & 13 & 106 & \multirow[t]{3}{*}{0.648} & \multirow[t]{3}{*}{$<0.001$} \\
\hline & & With retraction & 3 & 21 & 24 & & \\
\hline & \multicolumn{2}{|l|}{ Total } & 96 & 34 & 130 & & \\
\hline \multirow[t]{3}{*}{ Williams Syndrome } & \multirow[t]{2}{*}{ Evaluator 1} & Without retraction & 41 & 2 & 43 & \multirow[t]{3}{*}{0.482} & \multirow[t]{3}{*}{$<0.001$} \\
\hline & & With retraction & 0 & 1 & 1 & & \\
\hline & \multicolumn{2}{|l|}{ Total } & 41 & 3 & 44 & & \\
\hline
\end{tabular}

Table 4 Agreement (kappa/adjusted residual) between evaluator \#1 and \#2

\begin{tabular}{|l|l|l|}
\hline & $\begin{array}{l}\text { Kappa or adjusted } \\
\text { residual }\end{array}$ & $p$-value \\
\hline $\begin{array}{l}\text { Pars tensa retractions } \\
\text { (concordance) }\end{array}$ & 0.711 & $<0.001$ \\
\hline $\begin{array}{l}\text { Pars flaccida retractions } \\
\text { (concordance) }\end{array}$ & 0.65 & $<0.001$ \\
\hline $\begin{array}{l}\text { Pars tensa retractions } \\
\text { in Williams Syndrome }\end{array}$ & $-2.8^{*}$ & 0.011 \\
\hline $\begin{array}{l}\text { Pars flaccida retractions } \\
\text { in Williams Syndrome }\end{array}$ & $-2.6^{*}$ & 0.022 \\
\hline
\end{tabular}

${ }^{*}$ Adjusted residual.

specific investigation about this topic in the future. However, this variable does not change the outcome regarding the tympanic retractions.

We demonstrate a good agreement score (65-71\%) between the 2 independent and blinded evaluators about tympanic retractions. The "perfect" agreement would be something $\sim 0.8$ and 1.00 according to Landis et al. ${ }^{10}$ Evaluator \#2 was stricter about the presence of tympanic retractions in both groups and this probably has some influence in these results.

Ruah et al considered that the delay in absorption and differentiation of the mesenchymal could be responsible for the inability of elastin fibers in the tympanic membrane to mature, and that this delay could be a risk factor to encourage the development of retraction pockets as soon as the mattress mesenchymal disappeared. ${ }^{6}$ However, based on our findings, it seems that the elastin factor alone is not a risk factor for tympanic retractions.

\section{Conclusion}

The present study demonstrates that patients with WS are not more susceptible to retraction than controls. Subsequent studies should consider other factors and components of the tympanic membrane to be evaluated, especially inflammatory agents.

\section{References}

1 Ars BM. Tympanic membrane retraction pockets. Etiology, pathogeny, treatment. Acta Otorhinolaryngol Belg 1991;45(03):265-277

2 Yoon TH, Schachern PA, Paparella MM, Aeppli DM. Pathology and pathogenesis of tympanic membrane retraction. Am J Otolaryngol 1990;11(01):10-17

3 Tos M, Stangerup SE, Larsen P. Dynamics of eardrum changes following secretory otitis. A prospective study. Arch Otolaryngol Head Neck Surg 1987;113(04):380-385

4 Tos M. Upon the relationship between secretory otitis in childhood and chronic otitis and its sequelae in adults. J Laryngol Otol 1981;95(10):1011-1022

5 Ruah CB, Schachern PA, Zelterman D, Paparella MM, Yoon TH. Agerelated morphologic changes in the human tympanic membrane. A light and electron microscopic study. Arch Otolaryngol Head Neck Surg 1991;117(06):627-634

6 Ruah CB, Schachern PA, Paparella MM, Zelterman D. Mechanisms of retraction pocket formation in the pediatric tympanic membrane. Arch Otolaryngol Head Neck Surg 1992;118(12):1298-1305

7 Yan SD, Qiu ZM, Zhou NS. Ultrastructure of the secondary tympanic membrane in the human fetus. Acta Anat (Basel) 1988;131 (04):332-337

8 Chole RA, Kodama K. Comparative histology of the tympanic membrane and its relationship to cholesteatoma. Ann Otol Rhinol Laryngol 1989;98(10):761-766

9 Sadé J, Avraham S, Brown M. Atelectasis, retraction pockets and cholesteatoma. Acta Otolaryngol 1981;92(5-6):501-512

10 Landis JR, Koch GG. The measurement of observer agreement for categorical data. Biometrics 1977;33(01):159-174 